\title{
THE NUMERICAL SIMULATION SUPPORT TOOL FOR THE ASSESSMENT OF THE ACOUSTIC QUALITY OF WORSHIP SPACES
}

\author{
Benmaghsoula Hammou Zohra
}

Department of architecture and town planning, University of Constantine3, Algeria

\begin{abstract}
Because of its religious and social function, the mosque is a place of exchange and knowledge transfer of this knowledge, through the preaching of the imams in the form of speeches and reading the Qur'an during prayer. The mosques are therefore examples of public institutions where it is necessary ensure acoustic comfort, in order to obtain a good quality of listening. The mosque is also considered a building that has specific features associated with room acoustics, by its function as a place of listening; this characteristic has a direct impact on the design choices and consequently on user comfort. Thus, the quality of acoustic environments inside the mosque is strongly related to choices of design developed by the architect that must take into account in the beginning of the design; to ensure good sound quality, which unfortunately is far from the case. Our study attempts to answer the needs of designers, by assessing one of the most important criteria in room acoustics: the reverberation time. We will use for this purpose, the modelling and simulation tool to predict the acoustic quality of mosques by integrating the materials performance, which we will take it as a criterion of acoustic quality evaluated by the reverberation time. I use it in my research, acoustic simulation software EASE 4.4. In the area of room acoustics, these programs have reduced the complexity of the description of sound propagation phenomena in space. They allowed a simplification and mastery of acoustic phenomena. In second step, we will through different choices of materials, trying to optimize our reverberation time. This diagnosis can show us about the importance and contribution of each material for optimum sound quality inside the mosques.
\end{abstract}

\section{KEYWORDS}

Acoustic simulation, Mosques, Worship room, Acoustic comfort, Room acoustics.

\section{INTRODUCTION}

Mosques are spaces used for prayers, preaching, conferences and reciting the Quran. Due to its religious and social role, the mosque is regarded as a place where to exchange knowledge, which is transmitted by "imams", in the form of speech and by reading the Quran. During the prayers there are three distinctive acoustic requirements for mosques [1] hearing the imam's prayers, understand the sermon of the imam, listening and reciting the holy Quran. The worshippers participate in such activities always facing the "quibla", standing up lined in parallel ranges for different prayers. 
All practiced activities in mosques are linked to audibility and intelligibility of the speech witch is submitted to reverberation time. In room acoustics, the reverberation time is considered as the most important criterions to characterize audibility quality. Therefore, the mosques are models of public establishment where it is necessary to ensure an acoustic comfort to attain conditions of a good auditing quality. [2] Acoustics researches in mosques have permitted to put in evidence the acoustical problems of mosques, investigated by experimental methods such as measuring and data processing simulation [3]. Besides, proportions of the volume size, Most of the studies in this field have stressed the importance of coating materials, considering reverberation time as a main criterion of the acoustic quality.[4]

Hammad [5] conducted acoustics measurement in different mosques in Amman, the criteria evaluated were, RASTI, Early Decay Time (EDT) and Reverberation Time (RT). The acoustical performance was found to be poor for most of the mosques; the study of the great mosque of Amman has shown the impact of types of flooring on reverberation time. To improve the sound quality of these mosques, the materials of the walls and the carpet were changed. [6]

Abdou [7] also conducted similar study, with computer simulation to investigate the effect of mosque geometry on the acoustical performance. Examining different mosque shapes showed that the rectangular mosques, exhibited better spatial distribution for acoustical quality indicators than other shapes. A previous work Orfali's [8] study, has detailed the impact of primary structure (form, volume, walls, poles ) and secondary structure ( flooring, walls and poles covering) on the reverberation time values. $S " u$ and Yilmazer [9] studied the interior acoustics of Kocatepe Mosque in Ankara, Turkey. They found that the mosque has inadequate intelligibility of speech for the prayer mode, however, is a good place for reciting the musical version of the Holy Quran,

Most of these works have raised a common problem, which is the intensive use of hard surfaces, marble, tiles faience, glass. These materials often chosen for their aesthetic and ease of maintenance are reflective surfaces, with a low absorption coefficient The architectural design of a contemporary mosque, unfortunately often neglects the effect on its acoustical performance especially on the speech intelligibility; Most contemporary mosque designers do not pay attention to such requirements during the conceptual design stage. The acoustical behaviour, impact of acoustical material, and perception of sound inside the mosque prayer halls are rarely considered during the conceptual design stage. [10]

Several works have been published which studied the acoustical parameter historical mosques. The CAHRISMA project (Conservation of the Acoustical Heritage by Revival and Identification of Sinan Mosque's) aims, identification and preservation of acoustic and architectural heritage of Sinan's Mosques and Byzantine Churches in Istanbul. The project seeks to develop a new concept that is "hybrid architectural heritage"; this identification system analyzes the acoustic characteristics, as well as the visual aspects in a real time virtual environment [11]. Sinan.s Mosques and Byzantine Churches, which are worship spaces well known for their good acoustical qualities, are chosen as the building types to be utilized for the realization of that goal [12] The Architectural works of Sinan are among the most successful applications of acoustic science.

The acoustic absorption in mosques is too limited, and is just ensured by the carpet and worshippers. however the variation of the worshipper's number, who attend each daily prayer and Friday prayers, greatly affect the total absorption of sound in the mosque and make the 
reverberation time control more complex . This fact will have a negative impact on the listening comfort in the prayer hall because the reverberation time (RT60) measured or calculated will be very long, and this will seriously affect the speech intelligibility and clarity in the mosque.

The objective of this study is to evaluate the acoustic comfort in different empty mosque established in Constantine "Algeria" and proposed acoustic correction when this comfort is insufficient. The evaluation will be based on the reverberation time criteria according to Sabine. We will use numerical simulation as a tool to calculate reverberation time, and we will try through different material choices to optimize it taking as references, optimal values specific to mosques defined in the scientific literature.

Our article is divided into seven parts after the introduction in part 1, the recommended reverberation time values for mosques is defined in part 2, an overview on mosques selected in part 3. A presentation of the methodology and materials is presented in part 4, results and comparison in part 5, time reverberation simulation optimized and discussion in part 6 , and finally the conclusion in part 7.

\section{REVERBERATION TIME}

In room acoustics science, many indicators can be used in order to qualify the sound quality of speech. Examples of objective-based measures are RT, Definition (D50), Clarity (C50), Speech Transmission Index (STI), Rapid Speech Transmission Index (RASTI) and Articulation Loss of Consonants (percentage Alcon's). These parameters are given by the international standard ISO3382 [13].

In this study, the RT indicator was used for the assessment of the acoustic quality of mosques. The reverberation time is one the main used criteria to qualify the sound quality of speech. Reverberation is a phenomenon of the sound extension that we can notice in a closed space. Objectified a reverberation time, noted RT and expressed in seconds. The reverberation depends on the sound frequency so it is necessary to indicate time values of reverberation to different frequencies usually in octave scale. The first experiment of the acoustic characterization of a hall has been conducted by W.C Sabine (1868-1919). He established the formula, which measures time that a sound takes to be reduced until the limit of the audible. He found the quantitative correspondence, between the volume, the absorption of materials, and reverberation time of a room. Sabine formula is $T R(s)=0.16 \mathrm{VA}$.In this formula the RT60 is independent of the position of the source in the room and the listening position. "The Sabine formula presents the first quantitative and mathematical solution of a problem in room acoustics. From knowledge of materials and dimensions of the room, we could now predict the final reverberations time in the room "[14].

Reverberation time, is the time taken by the waves to subside after reflection on the walls of a room, compared to a drop in the loudness of $60 \mathrm{~dB}$, It varies according to the geometric proportions and coating of walls of the room. For spaces with very reflective walls and a large volume in the case of mosques, there may be powerful sound reflections from the floor, walls, columns and ceiling, and then there will be total confusion between sound Direct and reflected sound. In fact, when the imam's words are issued, they break down into direct sounds and reflected sounds. Of a certain distance from the source, the reverberation sound is more intensive than the direct sound. This phenomenon of interference between direct waves and reflected ones 
can engender echoes, which are produced when time interval that separate the arrival of two waves in the same point is superior to 0,1 second [15].

In this case, the reverberation is considered as harmful if it hides the successive sounds, speech becomes unintelligible, (we can say that vowels hide the consonants, which are no longer understood). On average 15-20 syllables are produced by a speaker per second, so each $70 \mathrm{~ms}$ to $50 \mathrm{~ms}$ (it depends on the speaker) there is a syllable produced in the room. Therefore, if long delayed reflections have a time longer than $50 \mathrm{~ms}$, the audience perceives a confused sound. Therefore, it is necessary to control reverberation, because it has a direct impact on intelligibility of speech. We will have to undertake acoustic correction, for bringing the reverberation time to an optimal value, depending on the nature of the space and its use. Most often, we have to reduce the reverberation time by increasing absorbent surfaces

\subsection{The recommended reverberation time values for mosques}

In Algeria, the normal values in terms of acoustic comfort are specifies in the regulatory technical document [16] elaborated by the national centre of research on buildings, related to housing and urbanism ministry. This document contains recommendations of reverberation time optimal values for space such as in classrooms, sport rooms and residential spaces. There are also in the scientific literature the recommended values of reverberation depending upon the use of space and its volume. [16]

It is also possible to use the approximate formula: $\mathrm{RT} 500 \mathrm{~Hz}=\mathrm{a} \log \mathrm{V}$ with $\mathrm{a}=0,28$ for a speech. Berg and Stork [17] require for speech a reverberation time inferior to 1 second in 500Hz. No normative value specific to mosques is provided in this documentation, to face this lack, we could take as a reference different researches on mosques, which have suggested reverberation time optimal values. Mainly A.Abdou [7] who has conducted a comparative study between mosques of different size, a mosque ranking on the basic of their volumes (eg, Table 1). Also Orfali .W [8] who has suggested according to this ranking of volumes, optimal values of reverberation time specifically tested on mosques (eg, Figure 1)

Table 1. Classification of mosques according to their volume into six groups

\begin{tabular}{|l|l|}
\hline Groups of mosques & The volume of the mosques \\
\hline A & $<1000$ \\
\hline B & $>1000<1500$ \\
\hline C & $>1500<2000$ \\
\hline D & $>2000<3000$ \\
\hline E & $>3000<10000$ \\
\hline F & $>10000$ \\
\hline
\end{tabular}




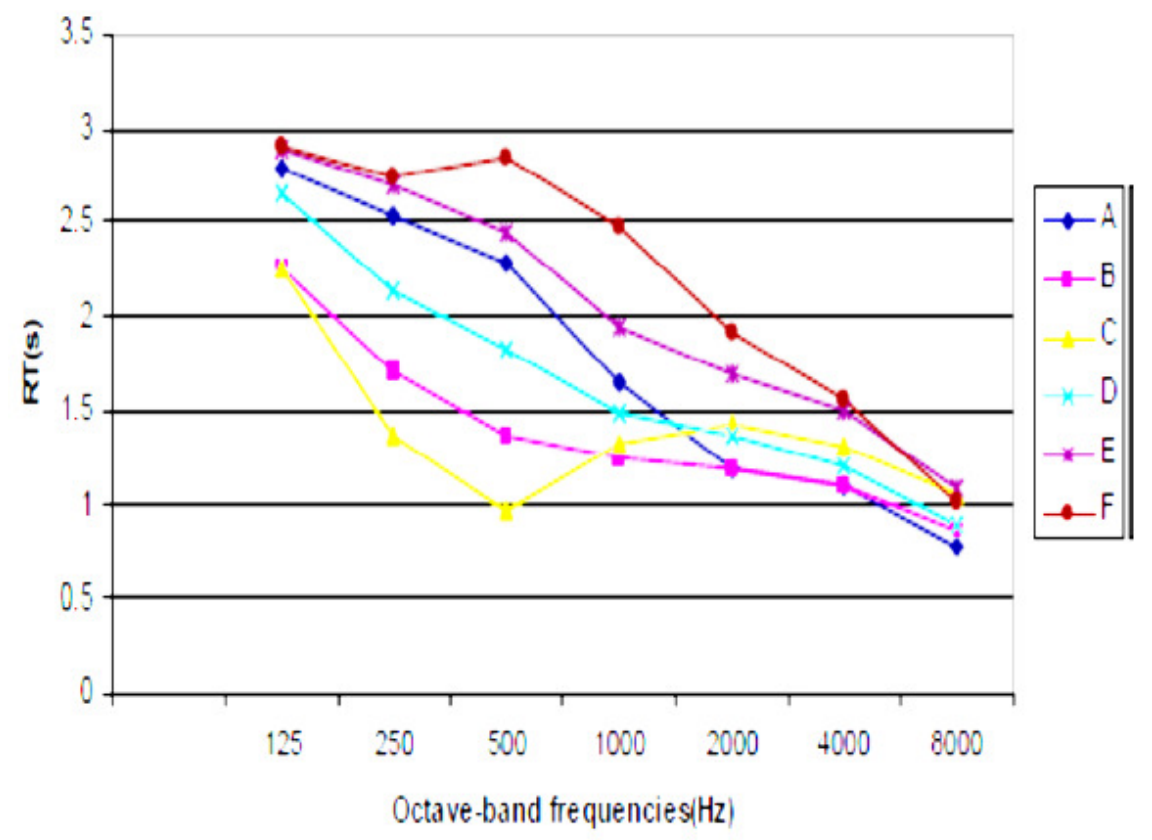

Figure 1. Reverberation time for different band frequencies for six groups of mosques

\section{AN OVERVIEW ON SELECTED MOSQUES}

The construction of mosques in Algeria is not different from other public buildings; it consists of a reinforced concrete frame with floor slabs and double low wall of brick. The particular architectural character of the mosque stands in the nature of finishing materials; they must combine ease of maintenance, durability and aesthetics, such as marble pottery and decorative plaster mouldings or sculptures on wood. The floor of the prayer hall is always covered with a rug or carpet; the walls are made at the bottom, by a marble tiled with veneer or paint finish in height.

The choice of the mosques purpose of our research, was done based on a ranking of their volumes, (eg, Table 2), according histogram illustrating the classification according to size (eg,Figure 2).The two mosques chosen for this study are in category $\mathrm{C}$, the most representative. The architecture of the two mosques, have similarities in exterior architectural design. The design of the prayer space has some differences, related to its surface, the number of columns, and the size of the mezzanine. 
Table 2. Mosques groups associated with their volumes.

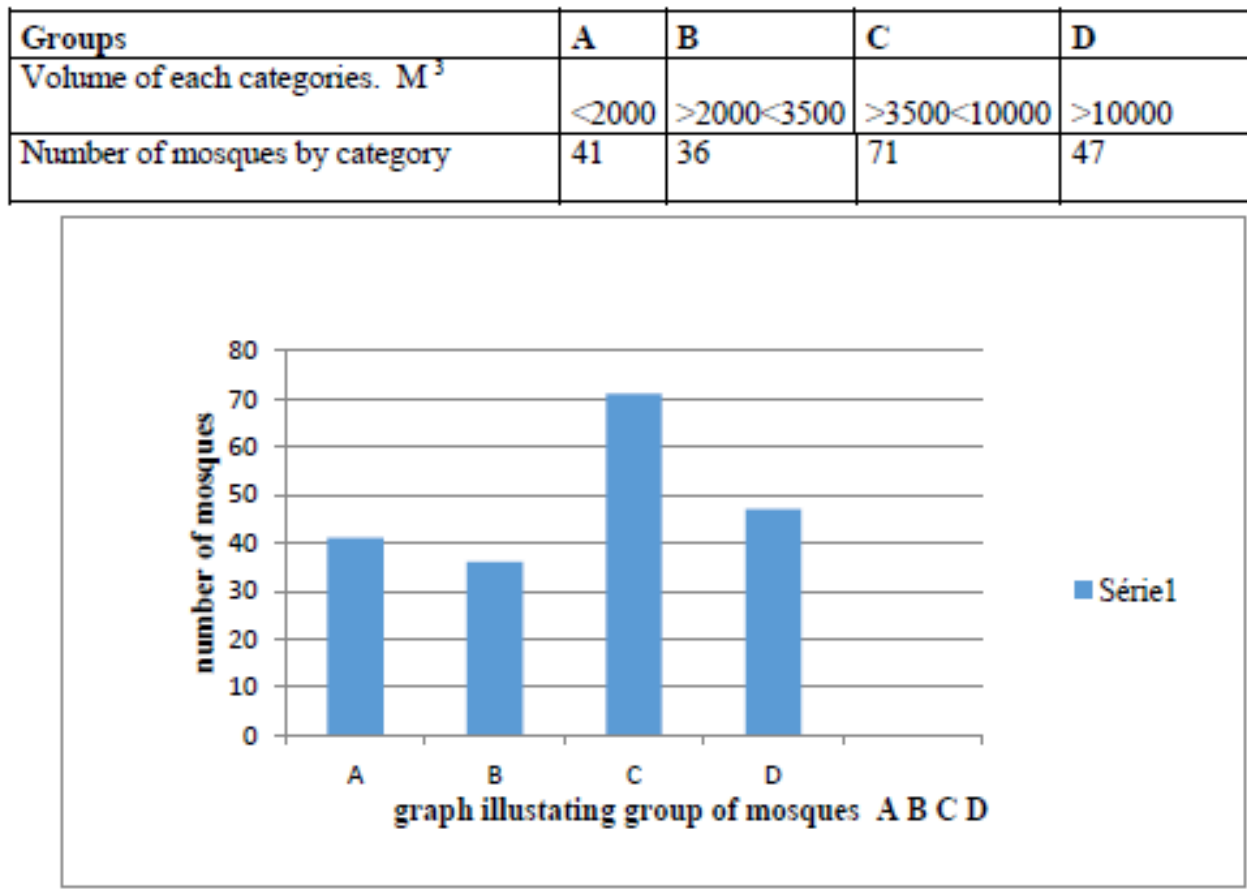

Figure 2. Graph illustrating the breakdown by categories of mosques surfaces of the wilaya of Constantine (data collected from the religious Affairs Directorate of the wilaya of Constantine 2013)

\subsection{Ibn-elarabi mosque.}

The design of the prayer hall of the mosque is a regular square of 30 meter from the side. (eg,Figure 3).Surmounted by a mezzanine floor covering two-thirds $2 / 3$ of its surface. It has four sets of poles parallel to qibla and five sets in the opposite direction. The floor is carped; the wall and poles are decorated, it consist of a veneer faience with a plaster painted in height. The dome is also in plaster decorated, it is 5 meters high, and off set from the geometric center of the mosque towards the qibla wall. All the mosque is a parallelepiped volume of $30 / 30 / 9 \mathrm{~m}$, which is characterized by very large opening divided into vertical band on all four front of the volume (eg, Photographs 1,2) 


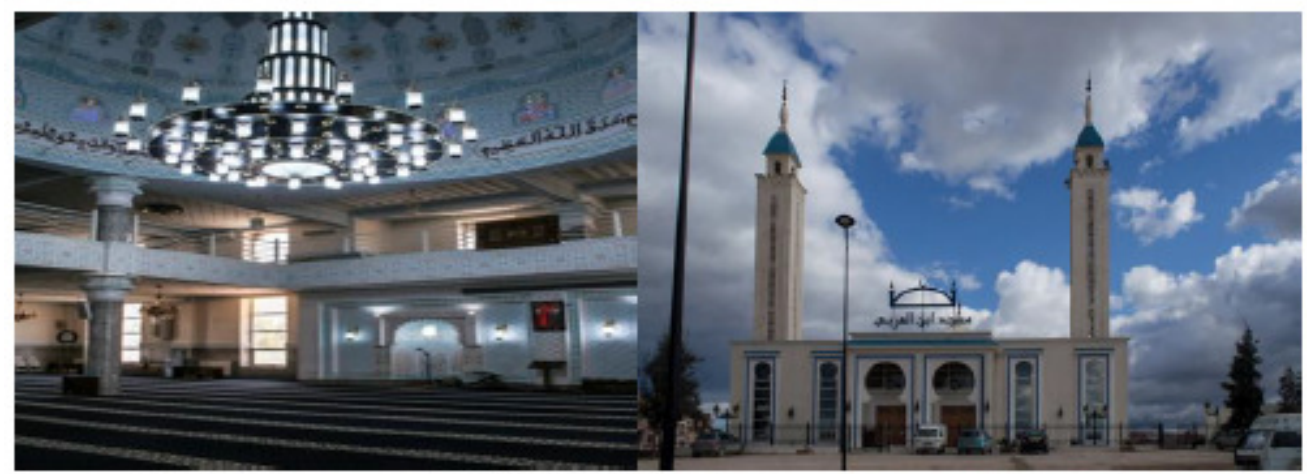

Photographs 1,2. interior and exterior of Ibn elarabi mosque

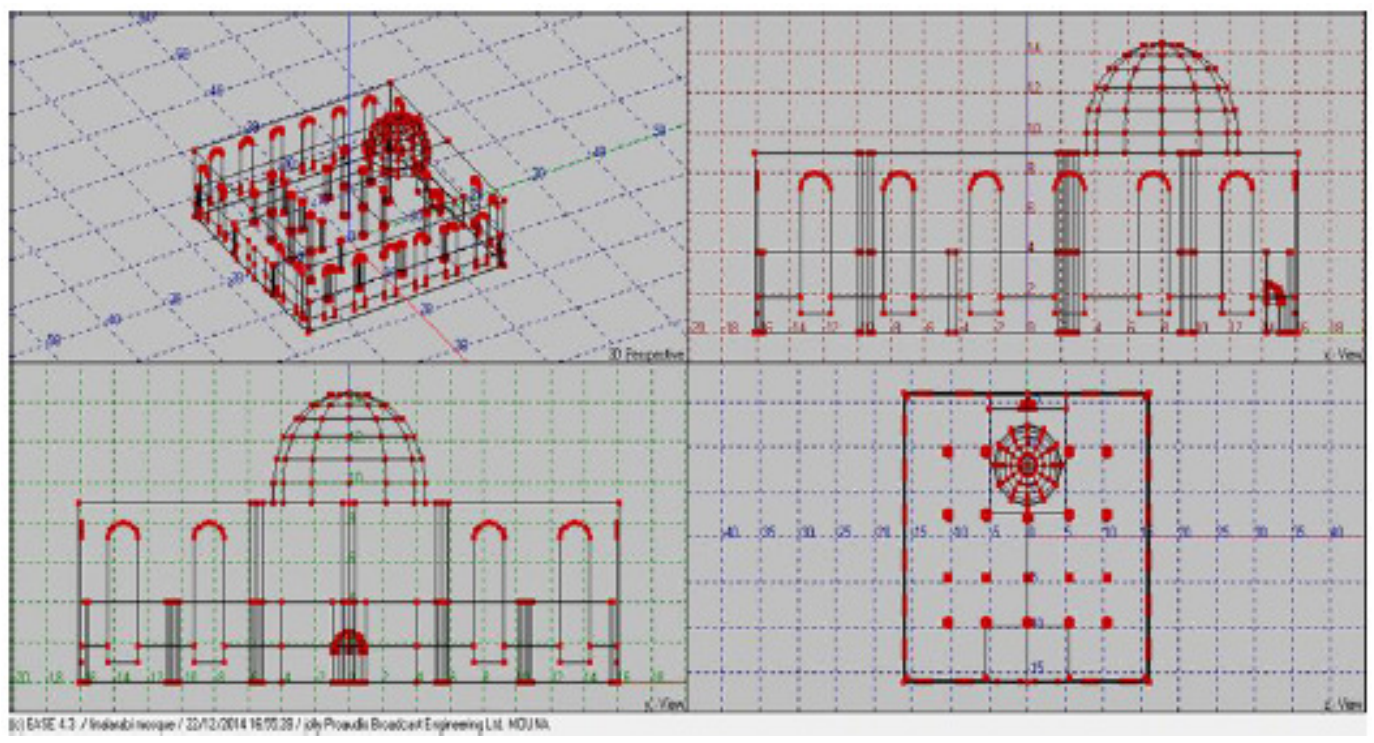

Figure 3. the Ibn-elarabi mosque modelled plan, section and elevation

\subsection{Ennoor Mosque.}

Ennoor mosque has a volume size less important than Ibn-elarabi mosque; the volume of the prayer room is more open since it only includes four pillars supporting the mezzanine floor and the dome, which situated in the mosque geometric center. . (eg,Figure 4) The finishing materials are similar to the previous mosque. The mezzanine floor holds $1 / 2$ of the surface of ground floor. The mosque forms a parallelepiped volume of 22/22/8 m and high of 14 meters below the dome. Prayer space is illuminated by ordinary openings distributed over the four walls, designed with multiple withdraws and advances. (eg, Photographs 3,4). 

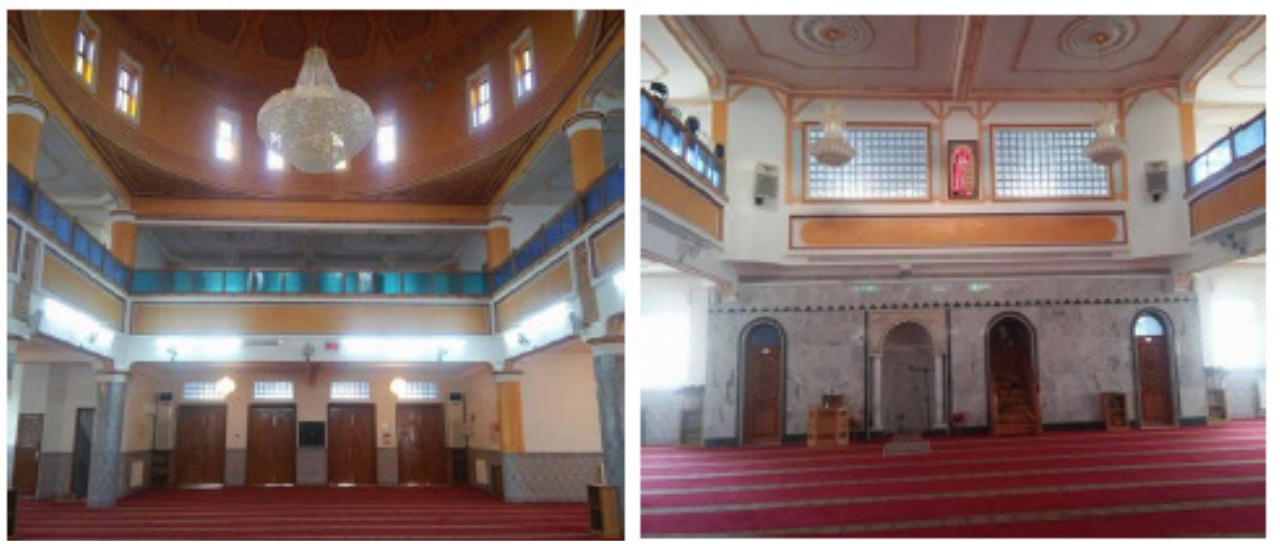

Photographs 3,4 interior of Ennoor mosque

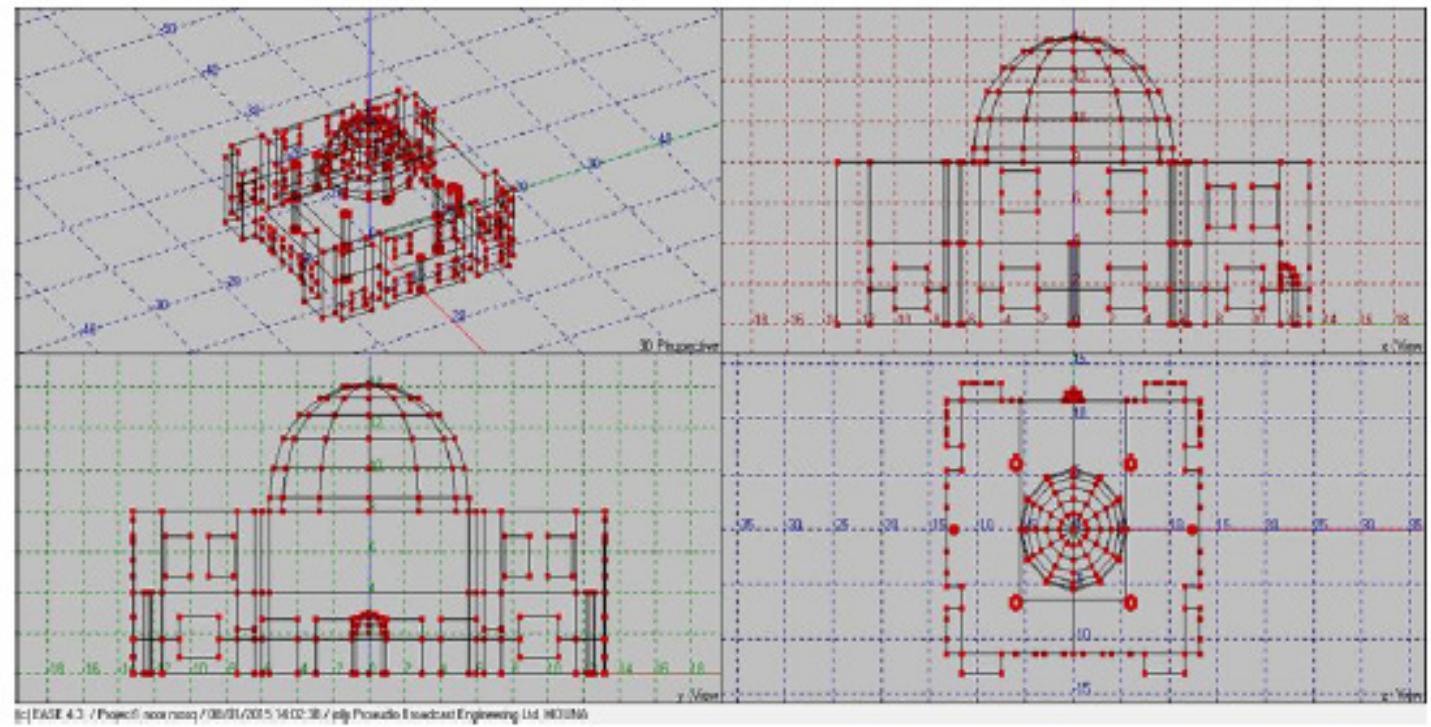

Figure 4. the mosque Ennoor modelled plan, section and elevation

\section{MATERIALS AND METHOD}

In almost all areas of knowledge, the study of phenomena, from the simplest to the most complex, goes through stages of modelling and simulation by using multiples numerical tools. Acoustic modelling and simulation are beneficial and effective computer-based tools in Room-acoustics. In our study, we shall use the acoustic simulation program, the EASE4.4, distributed by AFMG society. [18] EASE4.4 allows the modelling of acoustic and electro-acoustic room; with the ability to calculate many parameters used in room acoustics science. One of the most important criterion that we will calculate with the EASE 4.4 software is the reverberation time according to Sabine formula. 


\subsection{Materials.}

From the plans, sections and facades of two mosques, modelling with EASE 4.4 (unlike other software such as Catt, Odeon, Epidaurus) [19] provides a very powerful graphical environment to integrate the geometric model directly from its own interface entry. The ergonomics of EASE fits the needs of architects to model geometries loaded and rich in architectural elements and assignment of various materials, as is the case of mosques. The three-dimensional visualization of mosques (eg, Figures 3,4) are presented under the form of a digital model composed of facets to which acoustic parameters are associated, such as absorption coefficient of materials. Will be recalled, that asab absorption coefficient is the ratio between sound energy absorbed by a material, and the incident energy; it varies between zero and one as a function of the frequency.

\subsection{Methodology}

To concretize the objective defined in the introduction, we have prepared a methodological plan of four phases, illustrated in the organization chart (eg, Figure 5). We will conduct modelling of each mosque from the definition of the $3 \mathrm{D}$ geometry of the mosque and the absorbing properties of different materials walls (floor, ceiling, columns, and openings). The two mosques, has been modelled and simulated in the empty state without worshippers. After the geometric modelling and assigning materials with their absorption coefficients [on 125 to $8000 \mathrm{HZ}$ ]. The software EASE 4.4, calculate the reverberation time values. The computing of revrberation time, will be compared to the recommended values, then optimized by a more appropriate materials choice. Finally, we will conduct an analysis comparison on the obtained results.

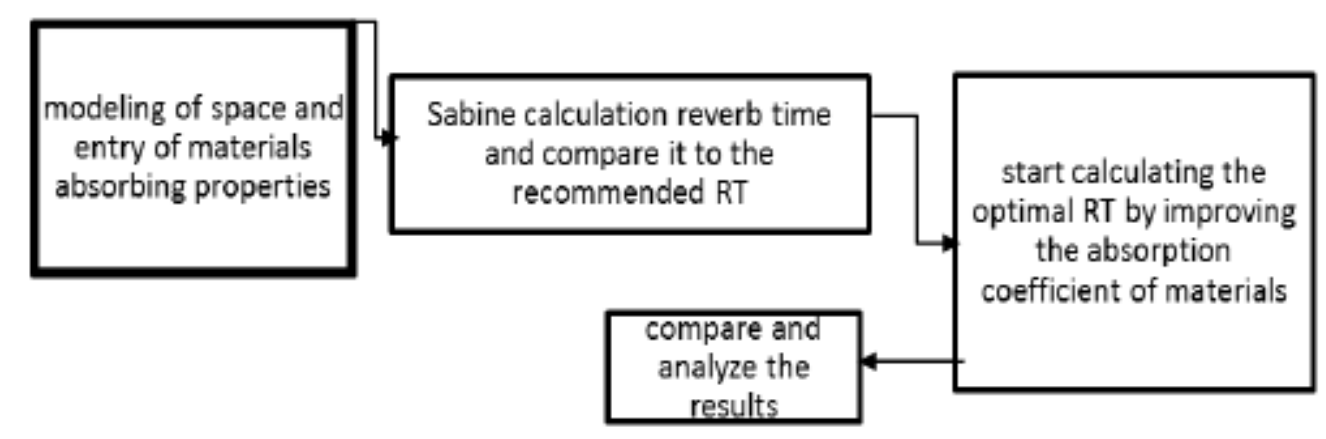

Figure 5. Flowchart of the research process

\section{PRESENTATION OF RESULTS AND COMPARISON.}

\subsection{EASE 4.4 modelling mosques}

Aura Ray Tracing tool provided in EASE 4.4 was used to take into consideration all architectural features and characteristics of the two mosques, and to investigate their influence on sound parameters. The Aura Analysis Utility for Room Acoustic Module is a very powerful. EASE 4.4 acoustical analysis tool Based on CAESER algorithms developed by Aachen University [RWTH], AURA allows the calculation of all key room acoustical parameters defined in ISO3382. [13] 
The value of RT by graph or table, of both mosques in empty state without worshippers, are directly given by EASE 4.4 after the geometric and the assignment of materials with the absorption coefficients, for different band frequencies using Aura Ray Tracing. By viewing the graph (eg, Figure 6) illustrating the absorption coefficients in the form of curves, we clearly notice except the floor carpet, all the others materials have very weak absorption coefficients, particularly in the range of low frequencies. On the histogram (eg, Figure 7) and the table (eg, Table 3) illustrating the percentage values of the materials used in the both mosque, we notice the percentage are too close in the use of the principal materials of both mosques except the carpet [ absorbing materials] which covers a very Important surface for Ennoor mosque. We also notice that a high percentage of the glasses [reflective materials] use in the great mosque, and a larger mezzanine floor which reduces the volume of the prayer space. Since $2 / 3$ of the space will have a height of 4 meters instead of 9 meters. At the end of the simulation, we could estimate the impact of architectural design on the values of reveberation time for the two mosques.

Table 3. Quantum properties of surfaces and materials used in the two mosques.

\begin{tabular}{|c|c|c|c|c|c|c|c|c|c|}
\hline \multirow{2}{*}{$\begin{array}{l}\text { mosques } \\
\text { Ennour }\end{array}$} & \multirow{3}{*}{$\begin{array}{l}\begin{array}{l}\text { Volume } \\
\mathbf{m}^{3}\end{array} \\
5382,98\end{array}$} & \multirow{3}{*}{$\begin{array}{l}\text { Area } \\
\mathbf{m}^{2}\end{array}$} & \multicolumn{5}{|c|}{$\begin{array}{l}\text { Different materials mosques estimated on } \\
\text { percentage }\end{array}$} & \multirow{3}{*}{$\begin{array}{l}\begin{array}{l}\text { Area } \\
\text { of the } \\
\text { mezza } \\
\text { nine }\end{array} \\
366,54 \\
\mathrm{~m}^{2}\end{array}$} & \multirow{3}{*}{$\begin{array}{l}\begin{array}{l}\text { Perce- } \\
\text { ntage } \\
\text { mezzani } \\
\text { ne }\end{array} \\
58,7 \%\end{array}$} \\
\hline & & & Plaster & marble & carpet & glasses & wood & & \\
\hline mosque & & & $71,16 \%$ & $7,19 \%$ & $18,53 \%$ & $2,34 \%$ & $0,78 \%$ & & \\
\hline $\begin{array}{l}\text { Ibn el } \\
\text { arabi } \\
\text { mosque }\end{array}$ & 9486,95 & 1036,8 & $71,86 \%$ & $7,75 \%$ & $16,19 \%$ & $3,82 \%$ & $0,38 \%$ & $\begin{array}{l}795,31 \\
m^{2}\end{array}$ & $76,60 \%$ \\
\hline
\end{tabular}


International Journal of Computer Science, Engineering and Information Technology (IJCSEIT), Vol. 6, No.1, February 2016

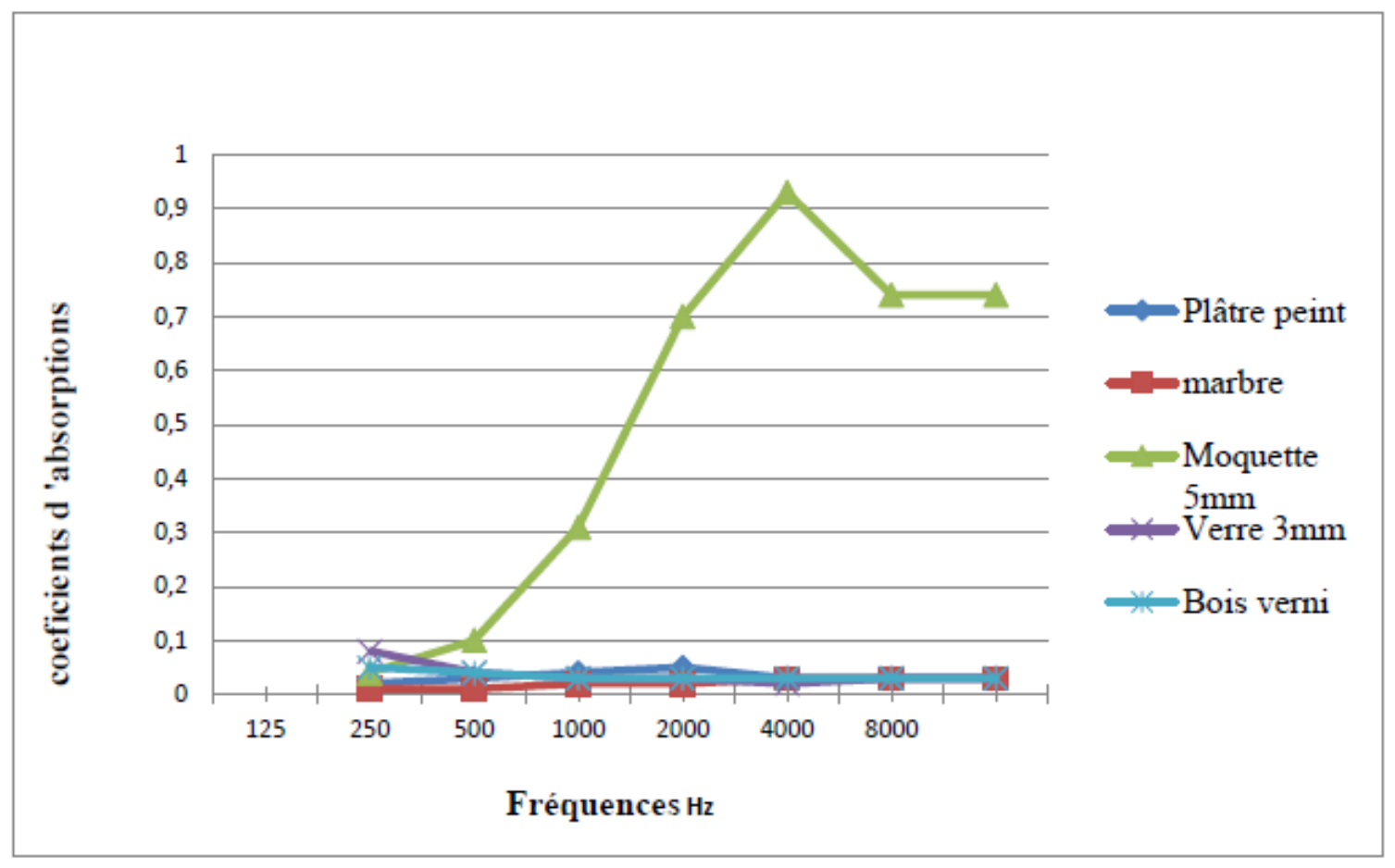

Figure 6. Curves showing the absorption coefficients of the two mosques materials

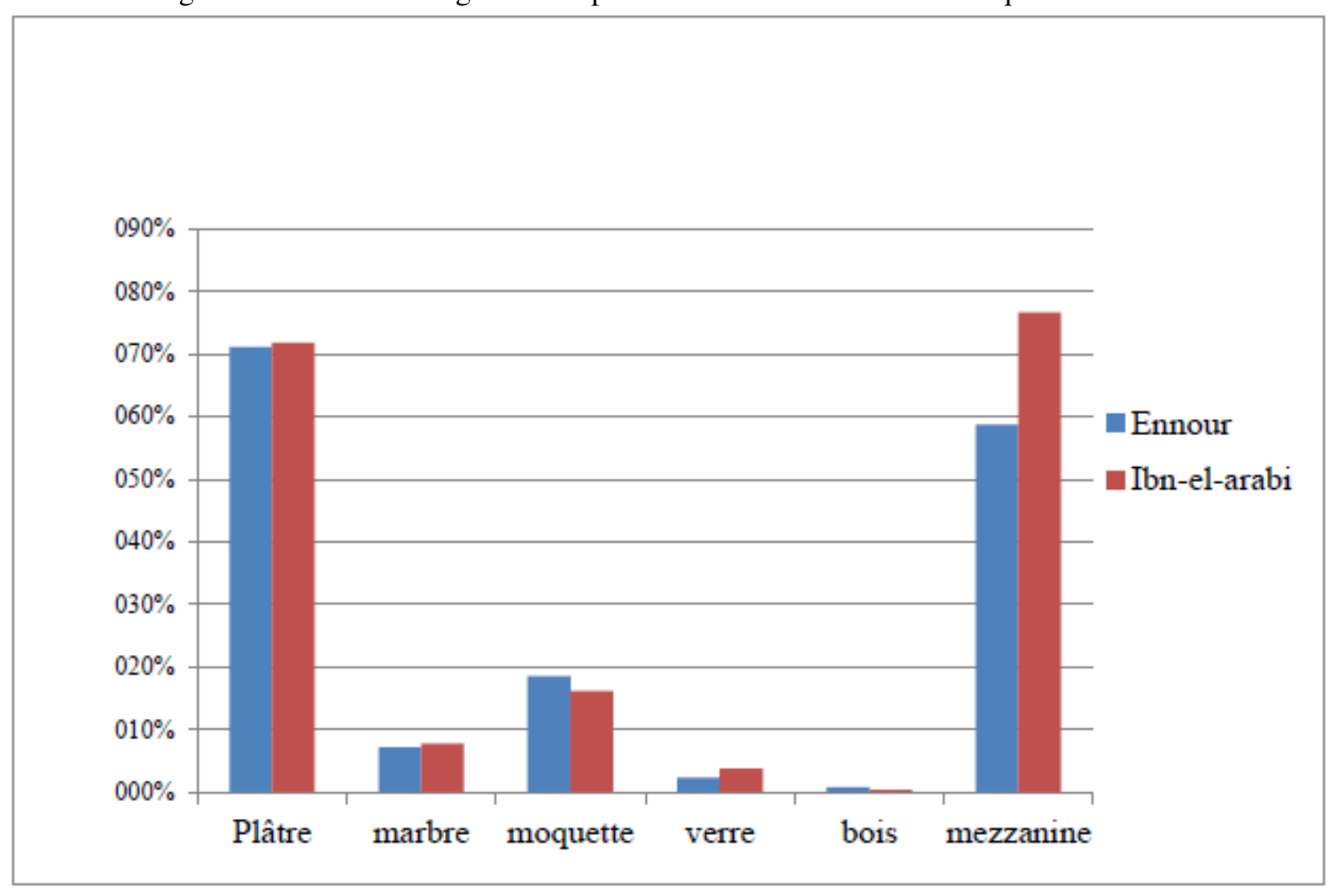

Figure 7. Histogram illustrates the percentage use of the two mosques materials 


\section{RESULTS}

\subsection{Reverberation time simulation of the two mosques.}

The values of reverberation time simulated for the two mosque provided by EASE 4.4 in octave band, for the frequency range $125 \mathrm{~Hz}$ to $1 \mathrm{kHz}$ (eg, Figure 8). We can observe a variation curve of RT depending on the frequency, very close between both mosques with a considerable difference, ten seconds, between the range of low and high frequencies. The RT500HZ for both mosques Ennoor and Ibn-elarabi are respectively of 2,95 and 3,27 seconds, for the given mosque volume $\mathrm{E}$ $>3000<10000 \mathrm{~m} 3$ the optimum RT500HZ value should be in the range of 2,4 s [8] . Taking into account the RT500HZ optimum level for mosques of these size, which is in the range of 2.4 seconds, we found a long RT and especially at low frequencies. (eg, Table 4).

The absorption coefficient of all materials in low frequencies is too weak, below 0,1 . Which gave excessive RT500HZ for the two mosques. 11, 69 and 10, 63 for respectively Ibn-elarabi and Ennoor, the RT500HZ optimum level for mosques is in the range of 3 seconds. Both mosques require a high level of audibility and intelligibility, we note that the high reverberation time does not ensure good listening conditions, for masking the speech elements which will pollute intelligibility. We can compare these values with other mosques. A comparison was done with values from two mosques in Algiers. A long reverberation time, has been also observed in these mosques El-forkane and El-ansar located in Algiers and simulated with the software CAAT acoustic [20]. We remark that for the 4 mosques (eg, Table 5) the reverberation time was superior to the required values. The highest value of RT concerns the mosque with the most important volume El-forkane. We can explain this difference by the fact that RT rises with the volume. Following these results, an acoustic correction of the mosques is done by reducing the reverberation to improve the intelligibility. This objective is attainable in case we treat the walls, ceiling and floor with absorbing materials.

Table 4. Comparison between recommended and simulated RT values for the two mosques

\begin{tabular}{|l|l|l|l|}
\hline & & & \\
Frequences & RT simulate ibn-el-arabi & RT simulate ennour & RT recommanded \\
\hline $125 \mathrm{HZ}$ & $\mathbf{1 1 , 6 8 \mathrm { s }}$ & $\mathbf{1 0 , 6 3 \mathrm { s }}$ & $\mathbf{3 s}$ \\
\hline $250 \mathrm{HZ}$ & $7,11 \mathrm{~s}$ & $6,24 \mathrm{~s}$ & $2,7 \mathrm{~s}$ \\
\hline $500 \mathrm{HZ}$ & $\mathbf{3 , 2 7 \mathrm { s }}$ & $\mathbf{2 , 9 5 \mathrm { s }}$ & $\mathbf{2 , 4 \mathrm { s }}$ \\
\hline $2000 \mathrm{HZ}$ & $1,37 \mathrm{~s}$ & $1,28 \mathrm{~s}$ & $1,7 \mathrm{~s}$ \\
\hline $4000 \mathrm{HZ}$ & $1,46 \mathrm{~s}$ & $1,37 \mathrm{~s}$ & $1,5 \mathrm{~s}$ \\
\hline $8000 \mathrm{HZ}$ & $0,98 \mathrm{~s}$ & $0,94 \mathrm{~s}$ & $1,2 \mathrm{~s}$ \\
\hline
\end{tabular}


Table 5. Comparison of RT values between the four mosques

\begin{tabular}{|l|l|l|c|}
\hline Mosques & RT simulate 500HZ & Volume m3 & RT Recommended 500 HZ \\
\hline El-forkane & $5,02 \mathrm{~S}$ & 13245,38 & $3 \mathrm{~s}$ \\
\hline El-ansar & $2,60 \mathrm{~S}$ & 9600 & $2,4 \mathrm{~s}$ \\
\hline Ennour & $2,95 \mathrm{~S}$ & 5382,98 & $2,4 \mathrm{~s}$ \\
\hline & & & $2,4 \mathrm{~s}$ \\
\hline Ibn-el-arabi & $3,27 \mathrm{~S}$ & 9486,95 & \\
\hline
\end{tabular}

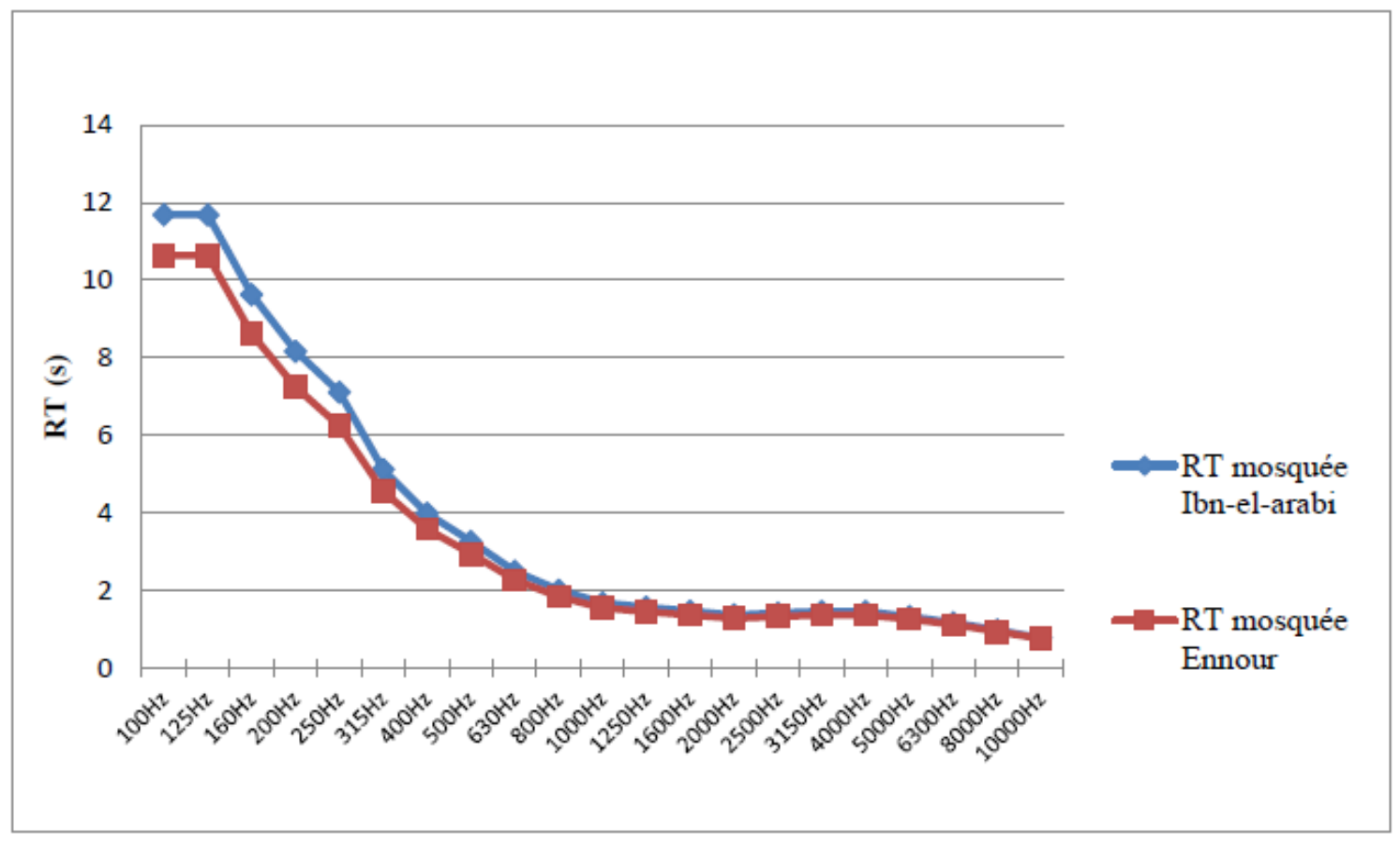

Figure 8. The values of reverberation time simulated for the two mosque provided by EASE 4.4 in octave band, for the frequency range $125 \mathrm{~Hz}$ to $1 \mathrm{kHz}$

\subsection{Simulation to optimize reverberation time}

As we previously said, reverberation time depend on the hall's volume and wall's absorbing materials. In Both simulated mosques, the use of materials of weak absorbing coefficient has caused an excessive reverberation that requires an acoustic correction to reduce it.so we have to use more absorbing walls materials. With EASE 4.4, modelling can be adjusted by activating interactive calculation window of the optimal reverberation time, which can assign new materials to the various walls of the space. We opted for the choice of available and less expensive. We 
proceed with a change at a time to judge the value of our choice in the improvement process of the reverberation time. Finally, we have associated all selected materials, and then have compared the initial RT with the optimized one. In addition, for that, we focused our choice on materials having a high absorbing coefficient to palliate the missing surface absorption. (eg, Table 6). The selected materials [ in the data base ] are for the floor, a carpet LPAD with an acoustical pad placed under the carpet, also the carpet PAD with a foam rubber under face, which is more recommended for the carpet treatment, since it absorbs more sound energy caused by the low and the mid frequencies compared to the LPAD carpet. The carpet PAD associates the textile face with open porosity [absorbing high frequencies] and foam rubber, which is porous and thick materials to absorb medium frequencies. (eg, Figure 9).

For windows, we have used wind glass with an absorbing coefficient in the range from 0,1 to 0 , 29 for frequency range [125 to $10000 \mathrm{~Hz}]$. Finally, we conducted a replacement of all marble covered surfaces with plaster, which is a more absorbing material for medium frequencies appropriate to speech. [19]

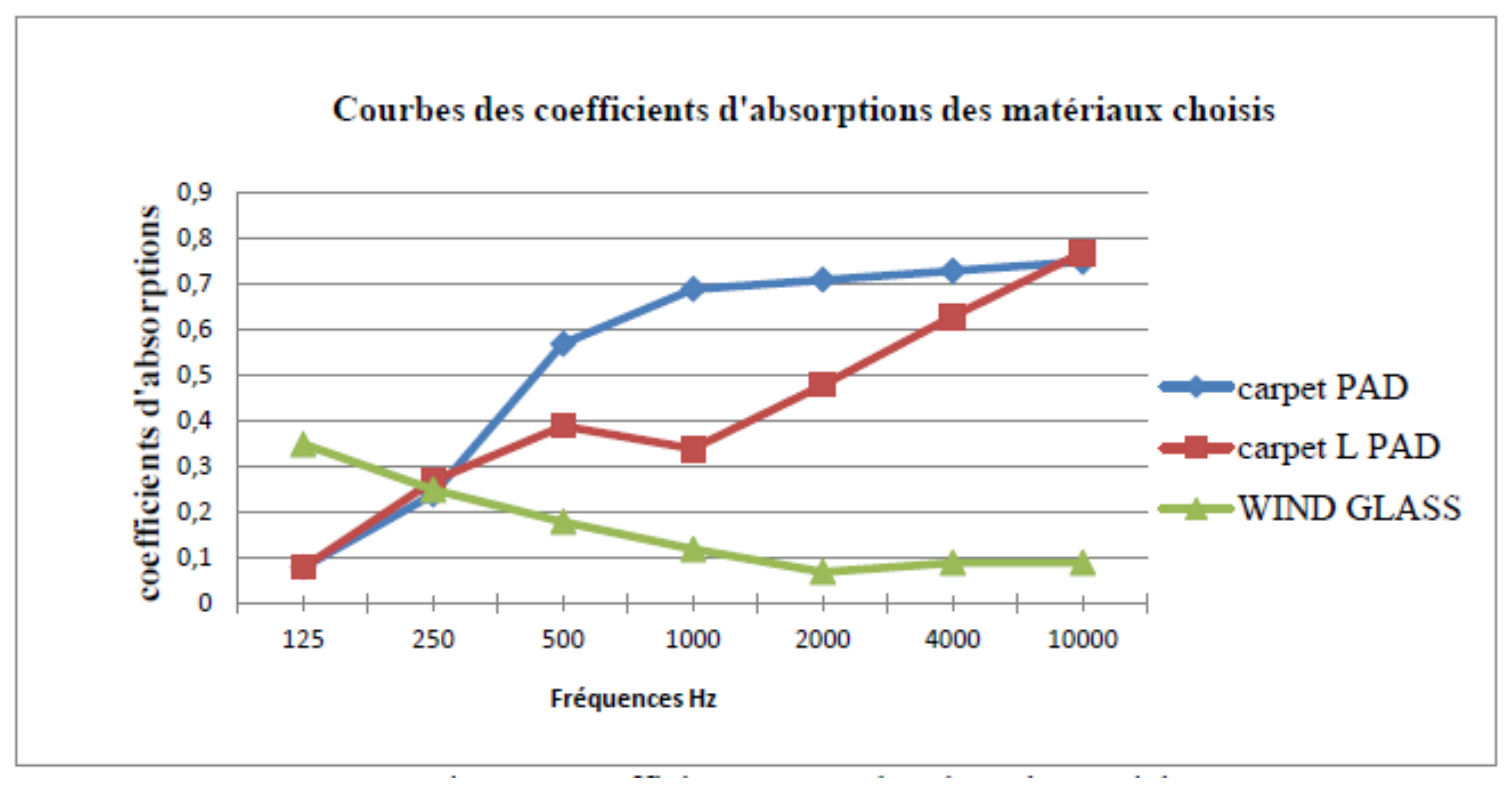

Figure 9 Coefficients removals selected materials

Table 6. Values of absorption coefficients of selected materials

\begin{tabular}{|l|l|l|l|}
\hline Frequencies Hz & Carpet PAD & Carpet L PAD & Wind glass \\
\hline 125 & 0,08 & 0,08 & 0,35 \\
\hline 250 & 0,24 & 0,27 & 0,25 \\
\hline 500 & 0,57 & 0,39 & 0,18 \\
\hline 1000 & 0,69 & 0,34 & 0,12 \\
\hline 2000 & 0,71 & 0,48 & 0,07 \\
\hline 4000 & 0,73 & 0,63 & 0,09 \\
\hline 10000 & 0,75 & 0,77 & 0,09 \\
\hline
\end{tabular}




\subsection{Optimized RT results}

The results of RT within all materials are shown in (eg, Figures 10 , 12). Respectively for Ennoor and El-arabi mosques. We observe a clear improvement of RT500Hz after the refitting done on finishing materials for both mosques. Making a successive replacement of materials, we notice that both mosques with carpet PAD , present the most reduced RT500Hz 1,9 seconds, compared to other changes of materials. An analysis on final optimized reverberation time, indicates a clear improvement of the RT to medium frequencies [500-1000 Hz] with respectively for the little and big mosques $1,7 \mathrm{~s}$ and 1,8 $\mathrm{s}$. Weak improvement is observed for low frequencies [100-300 Hz] the optimized RT125Hz respectively for the little and big mosques is 7,9 s and 5,6 s. It is higher than the required value for such category of volume which is evaluated to 3 seconds.[8] however, we notice that for the little mosque, the RT $125 \mathrm{~Hz}$ is only reduced by 2,4 seconds compared to RT125Hz of the great mosque which improves of 5,68 seconds. This phenomenon could be explained by the fact that the great mosque has got a more important percentage of glazed windows, and the wind glass[ compared to other materials] in the range of low frequencies has got superior alpha Sabine.

Table 7. Results of optimum reverberation time for Ennoor mosque.

\begin{tabular}{|l|l|l|l|l|l|l|}
\hline $\begin{array}{l}\text { Frequencies } \\
\mathbf{H z}\end{array}$ & $\begin{array}{l}\text { Initial } \\
\text { RT }\end{array}$ & $\begin{array}{l}\text { RT } \\
\text { carpet } \\
\text { Lpad }\end{array}$ & $\begin{array}{l}\text { RT } \\
\text { carpet } \\
\text { pad }\end{array}$ & $\begin{array}{l}\text { RT } \\
\text { plaster }\end{array}$ & $\begin{array}{l}\text { RT } \\
\text { wind } \\
\text { glass }\end{array}$ & RT optimized \\
\hline $\mathbf{1 2 5} \mathbf{H z}$ & $\mathbf{1 0 , 6 3}$ & $\mathbf{8 , 1 7}$ & $\mathbf{8 , 1 7}$ & $\mathbf{1 0 , 3 2}$ & $\mathbf{8 , 4 7}$ & $\mathbf{7 , 9 9}$ \\
\hline $250 \mathrm{~Hz}$ & 6,24 & 3,57 & 3,86 & 6,04 & 5,59 & 3,61 \\
\hline $\mathbf{5 0 0 H z}$ & $\mathbf{2 , 9 5}$ & $\mathbf{2 , 5 3}$ & $\mathbf{1 , 9 1}$ & $\mathbf{2 , 9}$ & $\mathbf{2 , 8 4}$ & $\mathbf{1 , 7 5}$ \\
\hline $1000 \mathrm{~Hz}$ & 1,55 & 2,55 & 1,56 & 1,53 & 1,53 & 1,28 \\
\hline $2000 \mathrm{~Hz}$ & 1,28 & 2,18 & 1,61 & 1,29 & 1,28 & 1,16 \\
\hline $\mathbf{4 0 0 0} \mathbf{H z}$ & $\mathbf{1 , 3 7}$ & $\mathbf{1 , 5 4}$ & $\mathbf{1 , 3 9}$ & $\mathbf{1 , 3 7}$ & $\mathbf{1 , 3 6}$ & $\mathbf{1 , 0 2}$ \\
\hline $10000 \mathrm{~Hz}$ & 0,76 & 0,74 & 0,75 & 0,76 & 0,75 & 0,62 \\
\hline
\end{tabular}

Table 8. Results of optimum reverberation time for Ibn-elarabi mosque

\begin{tabular}{|l|l|l|l|l|l|l|}
\hline $\begin{array}{l}\text { Frequencies } \\
\text { Hz }\end{array}$ & $\begin{array}{l}\text { Initial } \\
\text { RT }\end{array}$ & $\begin{array}{l}\text { RT } \\
\text { carpet } \\
\text { Lpad }\end{array}$ & $\begin{array}{l}\text { RT } \\
\text { carpet } \\
\text { pad }\end{array}$ & $\begin{array}{l}\text { RT } \\
\text { plaster }\end{array}$ & $\begin{array}{l}\text { RT wind } \\
\text { glass }\end{array}$ & RT optimized \\
\hline $\mathbf{1 2 5 H z}$ & $\mathbf{1 1 , 6 8}$ & $\mathbf{8 , 1 7}$ & $\mathbf{8 , 1 7}$ & $\mathbf{1 0 , 3 2}$ & $\mathbf{7 , 7 9}$ & $\mathbf{5 , 6 8}$ \\
\hline $250 \mathrm{~Hz}$ & 7,11 & 3,57 & 3,86 & 6,04 & 5,75 & 3,32 \\
\hline $\mathbf{5 0 0 H z}$ & $\mathbf{3 , 2 7}$ & $\mathbf{2 , 5 3}$ & $\mathbf{1 , 9 1}$ & $\mathbf{2 , 9}$ & $\mathbf{3 , 0 4}$ & $\mathbf{1 , 8 3}$ \\
\hline $1000 \mathrm{~Hz}$ & 1,68 & 2,55 & 1,56 & 1,53 & 1,65 & 1,53 \\
\hline $2000 \mathrm{~Hz}$ & 1,37 & 2,18 & 1,61 & 1,29 & 1,36 & 1,63 \\
\hline $\mathbf{4 0 0 0 H z}$ & $\mathbf{1 , 4 6}$ & $\mathbf{1 , 5 4}$ & $\mathbf{1 , 3 9}$ & $\mathbf{1 , 3 7}$ & $\mathbf{1 , 4 4}$ & $\mathbf{1 , 4}$ \\
\hline $10000 \mathrm{~Hz}$ & 0,78 & 0,74 & 0,75 & 0,76 & 0,77 & 0,75 \\
\hline
\end{tabular}


International Journal of Computer Science, Engineering and Information Technology (IJCSEIT), Vol. 6, No.1, February 2016

Table 9. Comparison optimized and recommended reverberation times

\begin{tabular}{|l|l|l|l|}
\hline $\begin{array}{l}\text { Frequencies } \\
\mathbf{H z}\end{array}$ & Ennoor RT optimized & $\begin{array}{l}\text { Ibn-el-Arabi RT } \\
\text { optimized }\end{array}$ & RT recommended \\
\hline $\mathbf{1 2 5} \mathbf{H z}$ & $\mathbf{7 , 9 9}$ & $\mathbf{5 , 6 8}$ & $\mathbf{3}$ \\
\hline $250 \mathrm{~Hz}$ & 3,61 & 3,32 & 2,7 \\
\hline $\mathbf{5 0 0 H z}$ & $\mathbf{1 , 7 5}$ & $\mathbf{1 , 8 3}$ & $\mathbf{2 , 4}$ \\
\hline $2000 \mathrm{~Hz}$ & 1,16 & 1,63 & 1,7 \\
\hline $\mathbf{4 0 0 0 H z}$ & $\mathbf{1 , 0 2}$ & $\mathbf{1 , 4}$ & $\mathbf{1 , 5}$ \\
\hline $10000 \mathrm{~Hz}$ & 0,62 & 0,75 & 1 \\
\hline Average & $\mathbf{2 , 7 1}$ & $\mathbf{2 , 4 6}$ & $\mathbf{2 , 0 5}$ \\
\hline
\end{tabular}

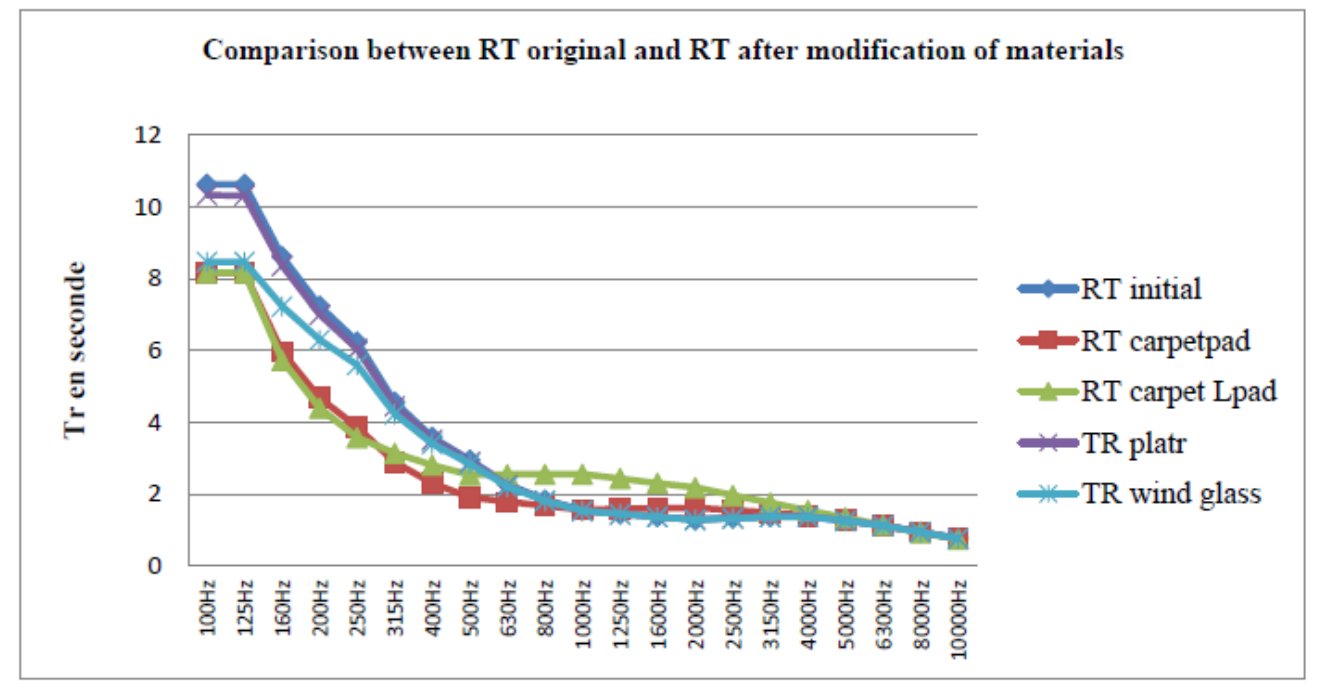

Fig 10. Comparison between the original RT and RT after modification of materials for Ennoor mosque.

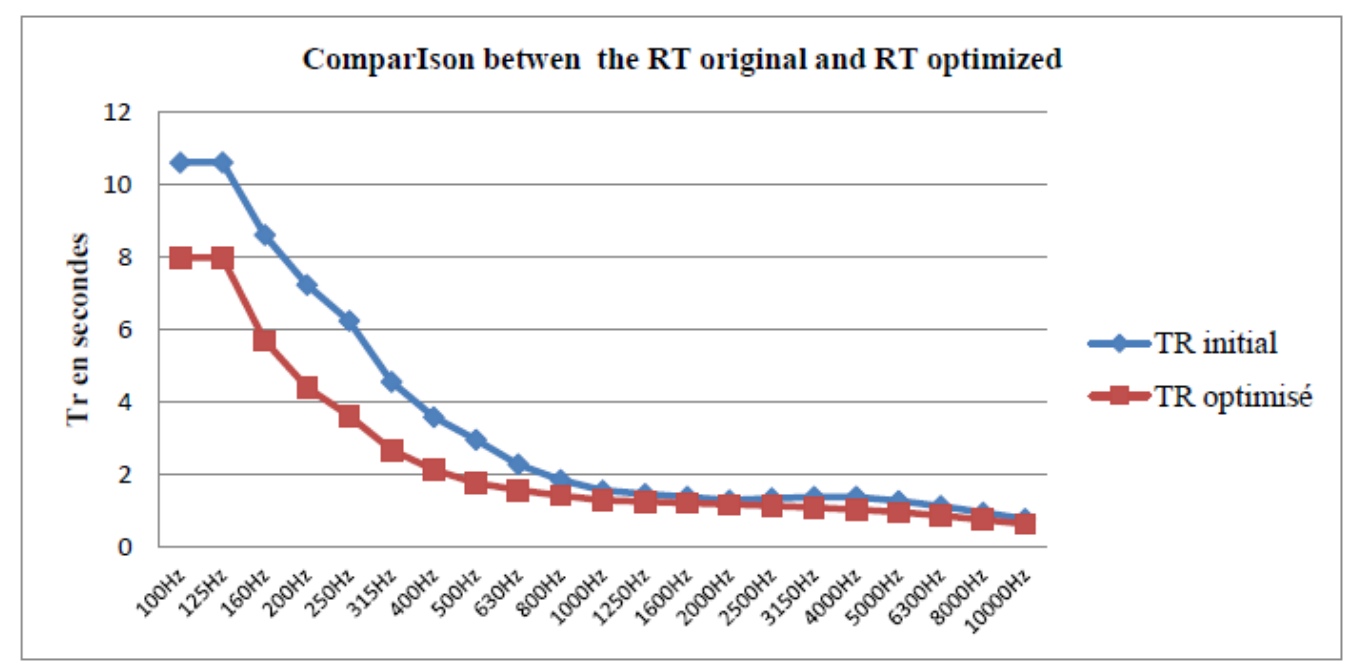

Fig 11 Comparison between the original RT and RT optimized final for Ennoor mosque 


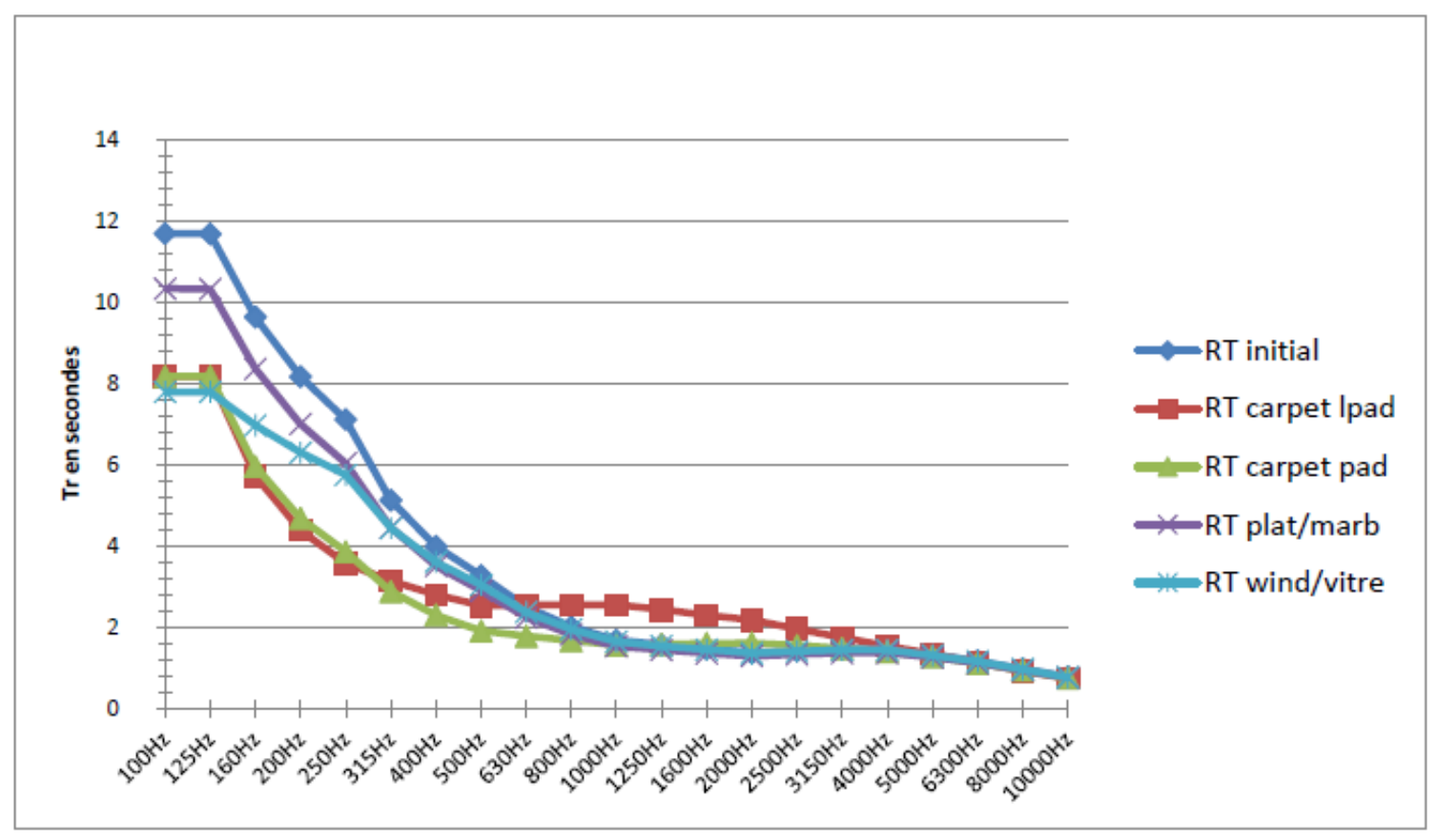

Fig 12 Comparison between the original RT and RT after modification of materials for Ibn-elarabi mosque.

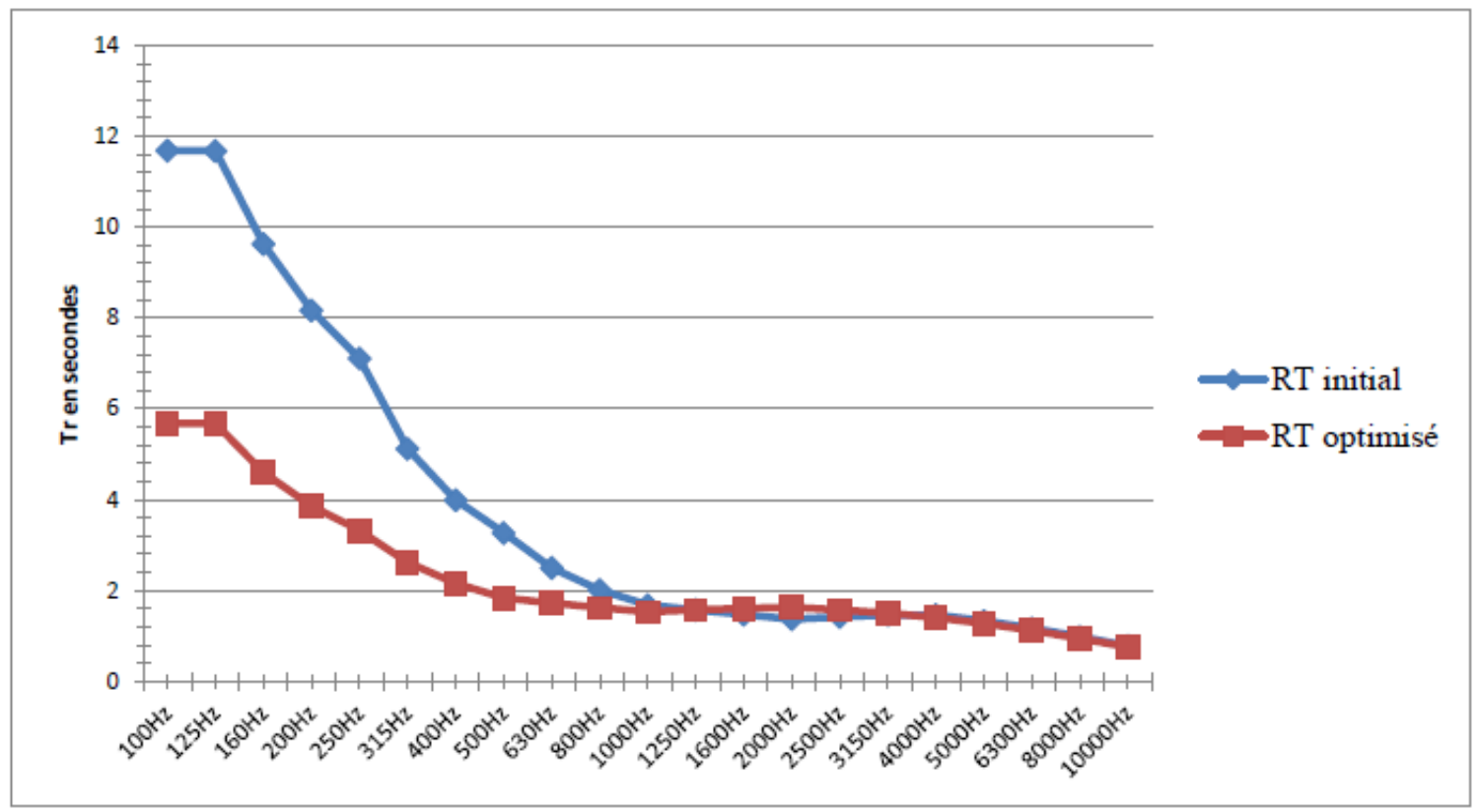

Fig 13. Comparison between the original RT and RT optimized final for Ibn-elarabi mosque

\subsection{Result's discussion}

Our study is an assay that permits in general the exploration of this new field investigation, which is the numerical simulation, applied to physical factors of architectural ambiance. Stressing the 
point of its importance for the architects to experiment this tool to conduct studies on building already realized or during the design phase. In the case of mosque's acoustics, our findings complete this research field, stressing the point on the importance of materials as a criterion to determine the evaluated acoustic quality by the reverberation time. This diagnostic has allowed us to learn about the importance and the contribution of some materials and architectural design to initiate the acoustic quality of mosques. In light of these results, we could make the following remarks.

- Results of the closest reverberation time, to the required value is obtained, by replacing the simple carpet by another one, with an important absorbing coefficient to high and medium frequencies. The carpet surface represent $1 / 5$ of the total surface of both mosques and the revrberation time has improved by one second and a few tenths. We can conclude that the choice of an appropriate carpet, constitutes a major criterion to take into consideration for ensure an optimum sound quality mosque.

- Comparing the optimized RT for both mosques, with the initial RT in different frequency ranges, we notice, that improvements have been different, in function of particularities of the architectural design of the two mosques. We also notice that the mezzanine surface can reduce prayer space volume and has a positive impact on reverberation time value, only if finishing absorbing materials is good selected.

- We can also mention the role of pilaster, it is preferable to opt for enlarge dimension between pilasters, and reduce their number for reducing the sound reflection. The reduction of columns number will permit to enlarge the carpet surface [principal absorbing materials] and improve the sound quality.

- By analysing RT variations optimized in function of different ranges of frequencies, medium, low and high ; we notice a progress in the medium and high frequency ranges; whereas in the low frequency range RT value remain excessively high, with double required value. This fact can be explained by the fact that there must be several modes of absorption of different materials in a space; for have a uniform absorption on the entire spectrum. The absorption with low frequencies needs materials such as membrane and resonator within complex implementations [21]. We can conclude that to release a uniform absorption on all the frequency range, it is necessary to use assembly or mixture of different materials in the same space.

\section{CONCLUSION}

In this study, we have conducted a research on acoustic characterization of two mosques built in Constantine [Algeria]. After modelling, the acoustic simulation has permitted to predict the acoustic quality of mosques with the integration of materials performances. The calculated reverberation time has been proved high compared to reverberation time recommended. Following this result, we have started a new stage of research in order to bring improvements by suggesting materials that are more absorbing. Our choice was made on simple organizations, which led to the reduction of the reverberation time in the middle frequencies specific to speech. The carpet role as an absorbing material has been proved crucial in reverberation time optimization. We can conclude a particular attention must be on the different space components, particularly, openings, columns, mezzanine floor, and further elements to carry on future research 
- Exploring the impact of the mezzanine design on the reverberation time values.

- Seek opportunities to optimize the reverberation time at low frequencies, by means of simple architecture.

- Studding the effect of the tridimensional geometric proportions [length, width, height] of the mosques on reverberation time values.

\section{REFERENCES}

[1] Zerhan, K. (1999). Acoustical Problem In Mosques, March 16, Yildiz Tech University.

[2] A.A. Abdou, (2003). "Measurement of acoustical characteristics of mosques in Saudi Arabia" The Journal of Acoustical Society of America, 113(3), 1505-1517

[3] Z. G Karabiber, (1999). "Acoustical problems in mosques: A case study on the three mosques in Istanbul”. Forum Acusticum, Berlin, CDROM, 4 pgs.

[4] Hossam Eldien and H Al Qahtani 2012 " The acoustical performance of mosques' main praye hall geometry in the eastern province, saudi Arabia". Proceedings of the Acoustics. Nantes Conference

[5] Hammad, R. N. S. (1990). "RASTI measurement in mosques in Amman, Jordan," Applied Acoustics, $30(4) 335-345$,

[6] Abdelazeez, M. K., Hammad, R. N and Mustafa, A. A. (1991). "Acoustics of King Abdullah Mosque",Journal of the Acoustical Society of America, 90 (3)1441-1445,

[7] Orfali, W. (2000) "Room Acoustic and Modern Electro-Acoustic Sound System Design during Constructing and Reconstructing Mosques", These Doctorat, Berlin

[8] S"u, Z and Yilmazer, S. (2007). The acoustical characteristics of the Kocatepe Mosque in Ankara, Turkey, Architectural Science Review, 51 (1), 21-30,

[9] Mostafa Refat Ismail (2013) "A parametric investigation of the acoustical performance of contemporary mosques" Frontiers of Architectural Research 2, 30-41 (2013) Available online www.sciencedirect.com

[10] Z. Karabiber Yüksel, C. Binan and R. Ünver (2003), "A Research Project in the Intersection of Architectural Conservation and Virtual Reality": Cahrisma. CIPA XIXth International Symposium, 30 September - 04 October, 2003, Antalya, Turkey.

[11] Z.K Yuksel, C. Binan, R. Unver, (2003). "A research project in the intersection of architectural conservation and virtual reality: CAHRISMA". In 19th International Symposium CIPA. Antalya, Turkey: Technical University of Istanbul.

[12] Acoustics-Measurement of the Reverberation Time of Rooms with Reference to Other Acoustical Parameters. ISO. 3382 International Standard, 2nd Edition (1997.)

[13] Remy, N. (2001) «maitrise et prédictibilité de la qualité sonore du projet architectural Applications aux espaces publics en gare ». Doctorat à l'École d'Architecture de Grenoble. Octobre(2001)

[14] Delétré,J.J. (2003) « Acoustique : propagation en espaces clos » - École d'architecture de Grenoble décembre.

[15] DTR C3.1.1, « Isolation acoustique des parois aux bruits aériens. Règles de calcul. Document technique règlementaire. »Centre National d'Etudes et de Recherche Intégrées du Bâtiments (CNERIB) (2004). Ministère de habitat et de l'Urbanisme (MHU).

[16] D. Templeton, (1993). "Acoustics in the Built Environment: Advice for the Design Team". Oxford: Butterworth

[17] Berg R.E \& Stork D.G. (1995) "The physics of sound", Prentice Hall.

[18] http://ease.afmg.eu licensed to the university of Constantine 3. (2015)

[19] Kouzeleas. S. (2002) «développement d'un outil d'aide en simulation acoustique architecturale adaptable a un système de modélisation c.a.o. «l'université bordeaux 1 école doctorale des sciences physiques et de l'ingénieur

[20] Bentafat,F. (2013) « Utilisation de la réponse impulsionnelle pour les mesures de l'acoustique des salles : application à l'amélioration de l'acoustique des mosquées » Magister . USTHB .Alger p. 58

[21] Mostefa Refat,I. (2013) "A parametric investigation of the acoustical performance of contemporary mosques". Frontiers of architectural research 2, 30-41. 


\section{Biography of Author}

Department of architecture and town planning, University of Constantine3 Algeria

Name first Name : Mme Benmaghsoula Zohra ép. Hammou.

Address $\quad:$ Bt G11 n 103 Ain smara 25140 Constantine. Algeria

Grade : Assistant teacher

Business address : département d'architecture et d'urbanisme, faculté d'Architecture et d'Urbanisme Université Constantine 3. Ville nouvelle Ali Mendjeli

Diploma : : Diploma of architect state, June 1985 Constantine.

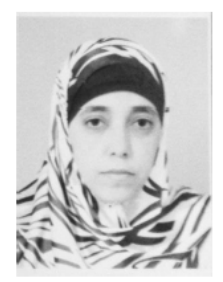
Magisterium in Bioclimatic Architecture December 1996 CONSTANTINE.

Doctorate in preparation: Relations between acoustic component and architectural design: acoustic characterization and improvement of the area of the mosque

\section{Training courses :}

- Training certificate in AUTOCAD à Constantine.

- Training for the handling of acoustic simulation software EASE 4.4 in Paris.

\section{Research Project (2015) :}

- Evaluation of the acoustic quality of listening places "Case of the amphitheaters of the Faculty of Architecture and Urbanism"

- Fields of interest: Bioclimatic architecture, architecture and Islamic urbanism. Architectural acoustics and room acoustics. Modeling and acoustic simulation. 